\title{
Serum CagA antibodies in asymptomatic subjects and patients with peptic ulcer: lack of correlation of IgG antibody in patients with peptic ulcer or asymptomatic Helicobacter pylori gastritis
}

\author{
D Y Graham, R M Genta, D P Graham, J E Crabtree
}

\begin{abstract}
Aim/background-Several studies have suggested that Helicobacter pylori which express CagA may be more virulent than those that do not, but limited populations have been studied to date. The aim of this study was to confirm and extend the association of CagA positive $H$ pylori strains in a different geographical area and to a large, well defined patient population.
\end{abstract}

Method-A validated ELISA for serum IgG to CagA was used to investigate the prevalence of CagA seropositivity in 100 patients with peptic ulcer compared with 77 with $H$ pylori infection without ulcer disease in a North American population. The extent of antral and corpus inflammation and $H$ pylori density in relation to CagA seropositivity in 40 subjects with $H$ pylori infection were assessed semiquanitatively. All studies were carried out in a coded and blinded manner.

Results-The prevalence of serum IgG CagA antibodies was higher in $H$ pylori infected patients with ulcer $(59 \%)$ compared with healthy $H$ pylori infected volunteers $(44 \%)$, but the difference was not significant. In contrast, the titre of serum IgG anti-CagA antibodies was higher among the seropositive subjects without ulcer disease, but again the difference was not significant. Comparison of histological features between asymptomatic individuals with $H$ pylori infection in relation to CagA IgG antibody status revealed no differences in infiltration with acute inflammatory cells, $H$ pylori density, or gastritis index. There was no relation evident between the degree of polymorphonuclear cell infiltration and the serum IgG antibody titre to CagA. Mononuclear cell infiltration in the antrum, but not the corpus, was greater in those with CagA IgG compared with those without (median score $5 v 3$ ).

Conclusions-A tight association between the presence or titre of serum IgG to CagA and peptic ulcer disease, greater $H$ pylori density or infiltration of the mucosa with acute inflammatory cells could not confirmed in a North American population. Perhaps geographical differences in the prevalence of circulating $\boldsymbol{H}$ pylori strains are responsible for the discrepant results reported.

(F Clin Pathol 1996;49:829-832)

Keywords: Helicobacter pylori, duodenal ulcer, gastric ulcer, CagA serology, pathogenesis, virulence factor.

Helicobacter pylori infection is now accepted as being intimately related to peptic ulcer disease, gastric carcinoma and primary $B$ cell gastric lymphoma. $H$ pylori infection is extremely common and yet only a small proportion of those affected develop a clinically significant outcome, such as peptic ulcer disease or gastric cancer. Diverse outcomes are not unusual with bacterial infections-for example, streptococcal infections are associated with diseases ranging from asymptomatic carrier state, sore throat, scarlet fever, rheumatic fever, cellulitis, to necrotising fasciitis. Clinical infectious disease usually represents an interplay between the bacterium and the host, and $H$ pylori infections are no exception. ${ }^{1}$ There are major research efforts underway attempting to unravel whether the bacterium or the host is the critical determinant of outcome for any particular $H$ pylori related disease.

The first putative virulence factor discovered that seemed to be associated with peptic ulcer disease was a vacuolating cytotoxin. ${ }^{2-4}$ This discovery was followed by identification of a systemic and mucosal humoral immune response to a $H$ pylori protein with a molecular weight of approximately $128000 .^{5}{ }^{6}$ The gene for this protein was cloned subsequently and because of its close association with the vacuolating cytotoxin, it was named the cytotoxin associated gene $\mathrm{A}(\operatorname{cag} A) .^{78}$ Several studies have shown that the prevalence of antibody to the CagA protein is higher in patients with peptic ulcer disease than in those with $H$ pylori gastritis without peptic ulcer disease. ${ }^{5-8}$ In addition, CagA expressing $H$ pylori have been reported to elicit a more severe local inflammatory response. This was initially ascribed to the ability of bacteria expressing this gene to stimulate robust interleukin-8 (IL-8) production by gastric epithelial cells in vitro. ${ }^{910}$ It was also shown that greater levels of gastric IL-8 and inflammation were observed in patients infected with CagA expressing $H$ pylori. ${ }^{11}$ Recently, however, it has been shown that the effect on IL-8 was associated with, but 
independent of, the presence of functional CagA. ${ }^{1213}$

Because the stomach may be infected with CagA positive and negative strains, it has been suggested that measurement of CagA IgG antibody is the preferred technique to detect the presence of these potentially more virulent bacteria. ${ }^{1415}$ The present study was designed to confirm and extend the association of CagA positive $H$ pylori strains in a different geographical area and to a large, well defined patient population.

\section{Methods}

Serum samples from patients with untreated and active duodenal or gastric ulcer or from asymptomatic controls with or without $H$ pylori infection were coded and tested blindly for the presence of IgG antibodies directed against CagA. $H$ pylori infection was confirmed by at least two tests, including histology (Genta stain), ${ }^{16} \mathrm{CLO}$-test, ${ }^{13} \mathrm{C}$ urea breath test, or $H$ pylori serum ELISA (HM-CAP, EPI, Westbury, New York, USA). There were no discordant values (for example, negative serology and positive urea breath test).

\section{CagA IgG ELISA}

Serum samples were assayed for CagA IgG antibodies by ELISA using as antigen a previously described purified 25500 molecular weight recombinant fragment of the CagA protein $^{17}$ (kindly provided by Dr A Covacci). Flat bottom microtitre plates (Falcon 3912, Becton Dickinson, Oxford, UK) were coated with $0.1 \mu \mathrm{g} /$ well antigen in $0.1 \mathrm{M}$ bicarbonate buffer, $\mathrm{pH} 9.6$, for 24 hours at $4^{\circ} \mathrm{C}$. After washing with phosphate buffered saline (PBS) containing $0.1 \%$ Tween-20 and blocking with $1 \%$ bovine serum albumin (BSA) in PBSTween (one hour, $26^{\circ} \mathrm{C}$ ), serum samples diluted 1 in 75 in 1\% BSA/PBS were assayed in duplicate. Following further washing and incubation with goat antihuman IgG alkaline phosphatase conjugate (Sigma, St Louis, Missouri, USA) bound antibodies were detected with pnitrophenyl phosphate substrate (Sigma) solution at $1 \mathrm{mg} / \mathrm{ml}$ in diethylolamine- $\mathrm{MgCl}_{2}$ buffer. A standard curve of high titre positive and control serum samples was included on each plate.

\section{RELATION BETWEEN CagA IgG STATUS AND} SEVERITY OF GASTRITIS

Forty cases were selected (16 with and 24 without CagA IgG) from the population with asymptomatic $H$ pylori gastritis to examine the possible relation between the presence, absence, or titre of CagA IgG and the histological findings. Those patients with serum IgG against CagA were chosen to represent the spectrum of antibody titres. Biopsy specimens of the gastric corpus and gastric antrum were examined separately by two pathologists without knowledge of the clinical diagnosis of the patient or the CagA IgG status. The severity of the infiltration with polymorphonuclear cells, mononuclear cells, number of $H$ pylori organisms, and a gastritis index (calculated by addi- tion of the score for polymorphonuclear cells and mononuclear cells) were determined.

\section{DATA ANALYSES}

Results were expressed in ELISA units (0-100) determined from the standard curve. The cutoff was determined as 9.25 ELISA units. It was calculated as the mean plus $3 \mathrm{SD}$ of the results obtained from 43 asymptomatic volunteers from the Houston area who were negative for $H$ pylori infection by the combination of negative serology, urea breath test, CLO-test, and histology (Genta stain of one corpus and two antral biopsy specimiens).

The results were first scored as positive or negative based on the cut-off value of 9.25 . For those with anti-CagA IgG the arithmetic mean titre was calculated. Proportions were compared using the $\chi^{2}$ test with Yates's correction. Titres were compared using the Mann Whitney rank sum test. The Student's $t$ test $\vec{t}$ could not be used because the data failed both the normality test and equal variance test. Statistical analyses were done using SigmaStat for Windows 1.0 (Jandel Corporation, San Rafael, California, USA).

\section{Results}

The study population consisted of 100 patients with endoscopically documented peptic ulcers, including 30 with gastric ulcer and 70 with duodenal ulcer disease. The control group consisted of 77 healthy $H$ pylori infected asymptomatic volunteers without endoscopic evidence of peptic ulcer disease.

Serum IgG CagA antibodies were present in $44.1 \%$ of healthy $H$ pylori infected volunteers and in $58.8 \%$ of patients with $H$ pylori and peptic ulcer, $57.7 \%$ of patients with duodenal ulcer and $63.3 \%$ of those with gastric ulcer. There was no significant difference in the prevalence of CagA seropositivity between volunteers and those with duodenal ulcer or gastric ulcer ( $p$ values were $0.28,0.12$ and 0.11 , respectively). The median titre of serum IgG anti-CagA antibodies was higher among the seropositive subjects without ulcer disease than those with $H$ pylori and peptic ulcer (32.5, 27, 26 and 33 for normal controls and patients with peptic ulcer, duodenal ulcer, and gastric ulcer, respectively) but the difference was not $N$ significant for any group $(p=0.19,0.16$ and $N$ 0.48 for peptic ulcer, duodenal ulcer and gastric ulcer, respectively).

Comparison of histological features between asymptomatic subjects with $H$ pylori infection in relation to IgG antibody status revealed no differences except for increased mononuclear cell infiltration in the antrum in those with CagA IgG (fig 1). The median score for $H$ pylori, polymorphonuclear cells, and mononuclear cells was identical (median 3 ) for the corpus and was one grade higher for the index in those with anti-CagA IgG (4 $v 3$ for presence compared with absence, $p=0.129)$. In the antrum the median score for $H$ pylori, polymorphonuclear cells and mononuclear cells was higher for those with CagA IgG seropositivity compared with those without ( $3 v 4$ for both $H$ pylori and polymorphonuclear cells and

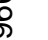

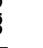

\section{,} 8 ํ. 을 , . 竞 

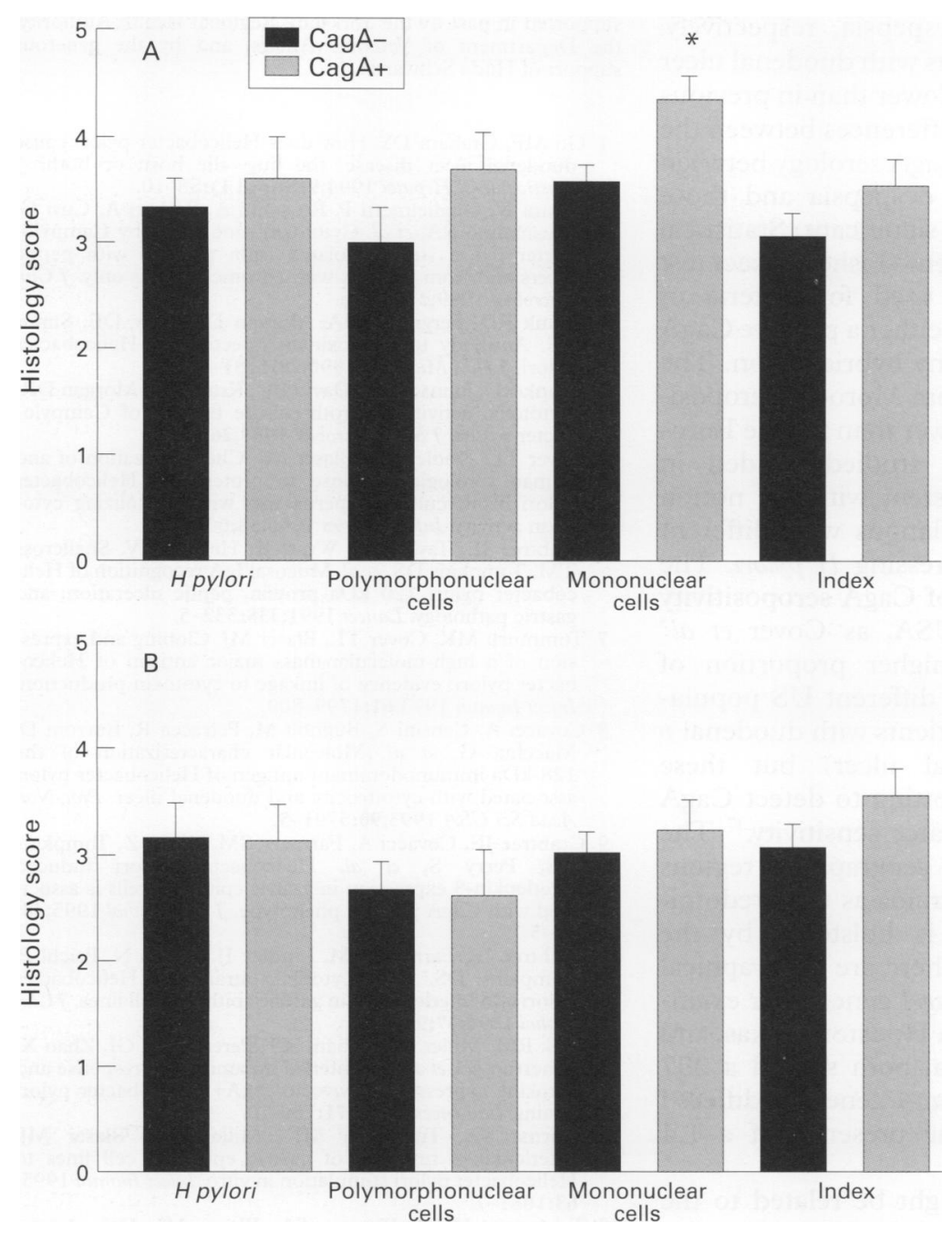

Figure 1 The density of $\mathrm{H}$ pylori, polymorphonuclear cell filtration, mononuclear cell infiltration, and gastritis index is compared for those with $\mathrm{H}$ pylori infection with and without CagA IgG seropositivity. The results are shown separately for the antrum $(A)$ and corpus (B). Data are presented as mean $(S E M) ;{ }^{*} p<0.05$.

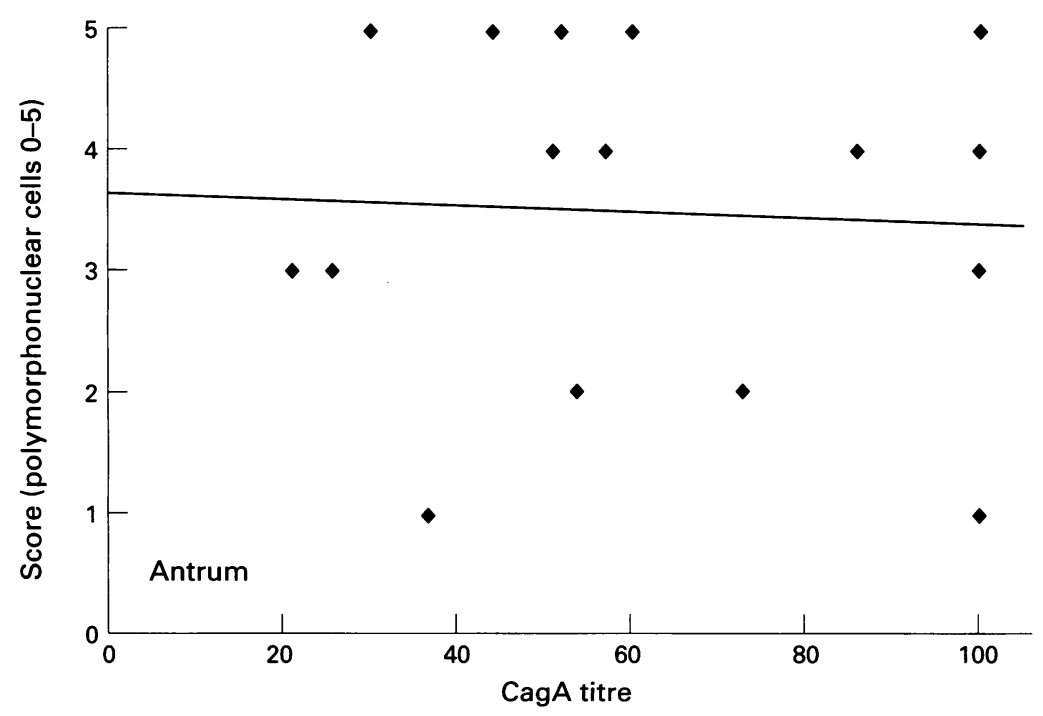

Figure 2 Comparison of the histological score for the density of polymorphonuclear cell infiltration and titre of CagA IgG. No correlation was found.

gastritis index, $\mathrm{p}=0.54,0.22,0.24$, respectively, and $3 v 5$ for mononuclear cell infiltration, $\mathrm{p}=0.03$ ).

Comparison of the degree of polymorphonuclear cell infiltration and the serum IgG antibody titre to CagA did not reveal any relation (fig 2).

\section{Discussion}

In this study population we did not observe a tight association between peptic ulcer disease and the presence of the serum IgG antibodies directed against CagA. Serum IgG CagA antibodies were found in $59 \%$ of the patients with peptic ulcer disease. CagA IgG seropositivity was slightly, but not significantly, greater in patients with duodenal ulcer disease than in asymptomatic controls. In addition, the antibody titre tended to be higher in the asymptomatic controls than in the patients with duodenal ulcer disease. We also did not find a positive association between the presence of serum IgG CagA antibody and the level of the acute inflammatory response to $H$ pylori infection. In contrast, we did find a significant increase in the number of mononuclear cells in the antrum of those with serum IgG CagA antibodies. Although there is concern about one statistically significant finding in data subjected to multiple comparison, similar observations on mononuclear cells have been made in European populations (Crabtree $\mathrm{JE}$, unpublished observations).

The assay used to detect the presence of anti-CagA IgG has been repeatedly validated and, therefore, we do not believe that the difference in results is due to the differences in technique for assessing serum IgG CagA antibody status. In addition, ours is the largest study to date and all evaluations were done blindly. The results are consistent with our previous experience in Houston. For example, the current data are also consistent with a larger study we carried out previously where we found that the most severe gastritis was in volunteers with asymptomatic $H$ pylori infection rather in those with duodenal ulcer disease. ${ }^{18}$ Although our results are internally consistent, it is possible that we cannot confirm previous observations because the prevalence of CagA expressing $H$ pylori differs between geographical regions. Such a difference would call into question the importance of $\operatorname{cag} A$ as a virulence factor. One would expect that an important virulence factor would relate to either a specific disease or to identifiable histological abnormalities. For example, if CagA expressing $H$ pylori were associated with production of IL-8, then neutrophil accumulation may be more evident in patients infected with these strains. However, the results presented here show that only the accumulation of mononuclear cells was significantly greater in the gastric mucosa of patients infected with CagA expressing $H$ pylori. This is unlikely to be linked to the induction of IL- 8 by strains of $H$ pylori as IL-8 interacts with two specific receptors that are expressed predominately on neutropils. ${ }^{1920}$ Although other reports infer that IL-8 may recruit or activate, or both, other cell types, studies to date have not definitively shown the expression of the specific receptor nor characterised any binding as specific except on neutrophils.

In other studies, Cover et al, ${ }^{15}$ using a different assay, reported serum IgG antibodies directed against CagA in $87.5 \%, 76 \%$, and $56.4 \%$ of patients with duodenal ulcer, gastric 
ulcer, and non-ulcer dyspepsia, respectively. The proportion of patients with duodenal ulcer with anti-CagA IgG was lower than in previous publications. $^{56817}$ The differences between the prevalence of a positive CagA serology between patients with non-ulcer dyspepsia and those with duodenal ulcer was significant. Statistical significance was not present (Fisher's exact test or $\chi^{2}$ test) when they used for criteria of positivity the presence of either a positive CagA serology or positive colony hybridisation. The proportion of subjects from Morocco seropositive for CagA was also lower than for the Europeans. The population studied resided in Belgium, which is consistent with the notion that there may be populations with different frequencies of $\operatorname{cag} A$ expressing $H$ pylori. The difference in frequency of CagA seropositivity also may vary in the USA, as Cover et $a l^{5}$ reported previously a higher proportion of CagA seropositivity in a different US population $(100 \% v 61 \%$ for patients with duodenal $v$ those without duodenal ulcer) but these authors used western blotting to detect CagA antibody, which has greater sensitivity. ${ }^{17}$ The hypothesis that different geographical regions have different $H$ pylori strains as the predominant circulating strain is bolstered by the recent observation that there are geographical allelic variations in the cag $A$ gene. ${ }^{21}$ For example, $H$ pylori isolates from Houston, Texas, and those from Seoul, Korea, both shared a 297 base pair region of the cag $A$ gene but differed remarkably regarding the presence of a 1.4 kilobase pair region. ${ }^{21}$

Another possibility might be related to the race of the subjects studied. We therefore compared the CagA antibody titres between whites and blacks. For both races the titre was higher for the asymptomatic $H$ pylori infected subjects compared with those with duodenal ulcer, with blacks having a slightly, but not significantly, higher titre than whites (median titres for blacks and whites, respectively, were $32.8 v$ 21.5 for those with duodenal ulcer and $51 v$ 26.5 for those with asymptomatic gastritis. There was also no difference in the scores for $H$ pylori density, polymorphonuclear cell or mononuclear cell infiltration between races.

In summary, we used different methodologies to investigate the possible association between CagA seropositivity with either peptic ulcer disease or with increased antral inflammation and failed to find a significant association. This study suggests that a general marker for more virulent $H$ pylori has not yet been discovered.

We thank Sarah Perry for her excellent technical assistance and Dr Peter Ernst for his helpful comments. The study was supported in part by the Yorkshire Regional Health Authority, the Department of Veterans Affairs, and by the generous support of Hilda Schwartz.

1 Go MF, Graham DY. How does Helicobacter pylori cause duodenal ulcer disease: the bug, the host, or both? Gastroenterol Hepatol 1994;9(Suppl 1):S8-10

2 Figura N, Guglielmetti P, Rossolini A, Barberi A, Cusi G, Musmanno RA, et al. Cytotoxin production by Campylobacter pylori strains isolated from patients with peptic lucter pylo strins isolated from ulcers and from patients 7:225-6.

3 Leunk RD, Ferguson MA, Morgan DR, Low DE, Simo AE. Antibody to cytotoxin in infection by Helicobacter pylori. $\mathcal{F}$ Clin Microbiol 1990;28:1181-4.

4 Leunk RD, Johnson PT, David BC, Kraft WG, Morgan DR Cytotoxic activity in broth-culture filtrates of Campylobacter pylori. 7 Med Microbiol 1988;26:93-9.

5 Cover TL, Dooley CP, Blaser MJ. Characterization of and human serologic response to proteins in Helicobacter pylori broth culture supernatants with vacuolizing cytopylori broth culture supernatants with vacuo

6 Crabtree JE, Taylor JD, Wyatt JI, Heatley RV, Shallcross TM, Tompkins DS, et al. Mucosal IgA recognition of Helicobacter pylori $120 \mathrm{kDa}$ protein, peptic ulceration, and gastric pathology. Lancet 1991;338:332-5.

7 Tummuru MK, Cover TL, Blaser MJ. Cloning and expression of a high-molecular-mass major antigen of Helicobacter pylori: evidence of linkage to cytotoxin production. Infect Immun 1993;61:1799-809.

8 Covacci A, Censini S, Bugnoli M, Petracca R, Burroni D, Macchia G, et al. Molecular characterization of the $128-\mathrm{kDa}$ immunodominant antigen of Helicobacter pylori associated with cytotoxicity and duodenal ulcer. Proc Natl Acad Sci USA 1993;90:5791-5.

9 Crabtree JE, Covacci A, Farmery SM, Xiang Z, Tompkins DS, Perry S, et al. Helicobacter pylori induced interleukin-8 expression in gastric epithelial cells is associated with CagA positive phenotype. F Clin Pathol 1995;48: $41-5$.

10 Crabtree JE, Farmery SM, Lindley IJ, Figura N, Peichl P, Tompkins DS. CagA/cytotoxic strains of Helicobacter pylori and interleukin-8 in gastric epithelial cell lines. $\mathcal{F}$ Clin pylori and interleukin-8
Pathol $1994 ; 47: 945-50$

11 Peek RM, Miller GG, Tham KT, Perez-Perez GI, Zhao X, Atherton JC, et al. Heightened inflammatory response and cytokine expression in vivo to cagA + Helicobacter pylori strains. Lab Invest 1996;71:760-70.

12 Sharma SA, Tummuru MK, Miller GG, Blaser MJ. Interleukin-8 response of gastric epithelial cell lines to Helicobacter pylori stimulation in vitro. Infect Immun 1995; 63:1681-7.

13 Tummuru MKR, Sharma SA, Blaser MJ. Helicobacter pylori picB, a homologue of the Bordetella pertussis toxin secretion protein, is required for induction of IL-8 in gastric epithelial cells. Molecular Microbiology 1995;1:86776.

14 Peek RM Jr, Miller GG, Tham KT, Perez-Perez GI, Cover TL, Atherton JC, et al. Detection of Helicobacter pylori gene expression in human gastric mucosa $\mathcal{f}$ Clin Microbiol 1995;33:28-32.

15 Cover TL, Glupczynski Y, Lage AP, Burette A, Tummuru MK, Perez-Perez GI, et al. Serologic detection of infection with cagA + Helicobacter pylori strains. 7 Clin Microbiol with cagAt Helico

16 Genta RM, Robason GO, Graham DY. Simultaneous visualization of Helicobacter pylori and gastric morphology: a new stain. Hum Pathol 1994;25:221-6.

17 Xiang Z, Bugnoli M, Ponzetto A, Morgando A, Figura N, Covacci A, et al. Detection in an enzyme immunoassay of an immune response to a recombinant fragment of the 128 kilodalton protein (CagA) of Helicobacter pylori. Eur $\mathcal{f} \mathrm{N}$ klin Microbiol Infect Dis 1993;12:739-45.

18 Graham DY, Klein PD, Evans DJ Jr, Evans DG, Alpert LC, N Opekun AR, et al. Campylobacter pylori detected noninvasively by the 13C-urea breath test. Lancet 1987;i:1174-7.

19 Thomas KM, Taylor L, Navarro J. The interleukin-8 receptor is encoded by a neutrophil specific cDNA clone, F3R. $\mathcal{F}$ Biol Chem 1991;266:4839-41.

20 LaRosa GJ, Thomas KM, Kaufmann ME, Mark R, White $\mathrm{M}$, Taylor $\mathrm{L}$, et al. Amino terminus of the interleukin-8 receptor is a major determinant of receptor subtype specifireceptor is a major determinant of rece

21 Miehlke S, Kibler K, Kim JG, Figura N, Small SM, Graham DY, et al. Allelic variation in the cagA gene of Helicobacter pylori obtained from Korea compared to the United States. Am $\mathcal{f}$ Gastroenterol 1996;91:1332-5. 